\title{
Elecciones bajo sospecha. Análisis de las elecciones generales en Honduras 2017
}

\author{
Cecilia Graciela Rodríguez (España)*
}

\section{Resumen}

Este artículo aborda el último proceso electoral hondureño, iniciado en marzo de 2017 con las Elecciones Primarias y concluido el 26 de noviembre de ese mismo año con las cuestionadas Elecciones Generales que dieron como ganador a Juan Orlando Hernández, candidato por el oficialista Partido Nacional de Honduras $(\mathrm{PNH})$, tras imponerse en las urnas por un estrecho margen de votos que puso en entredicho al Tribunal Supremo Electoral por la sospecha de fraude electoral. Para ello, se mencionan las principales características del sistema de partidos hondureño, se describe el contexto político, social y económico previo a las elecciones, se abordan los procesos electorales acaecidos en 2017, y se analizan sus resultados y las consecuencias de estas para el sistema de partidos. Se concluye que el golpe de Estado de 2009, los resultados electorales de 2013 y 2017, y el desempeño del Gobierno en el ámbito socioeconómico ha provocado el descontento ciudadano, la desconfianza en las familias políticas tradicionales y la renovación de la clase política hondureña.

Palabras clave

Sistema Electoral; Elecciones; Cambio Político; Partidos Políticos; Honduras.

Fecha de recepción: agosto de 2018

- $\quad$ Fecha de aprobación: octubre de 2018

\section{Cómo citar este artículo}

Rodríguez, Cecilia Graciela. (2019). Elecciones bajo sospecha. Análisis de las elecciones generales en Honduras 2017. Estudios Políticos (Universidad de Antioquia), 54, pp. 203-232. http://doi.org/10.17533/udea.espo.n54a11

\footnotetext{
* Licenciada, magíster y doctora en Ciencia Política. Investigadora del Instituto Universitario de Iberoamérica de la Universidad de Salamanca y miembro del Proyecto Elites Parlamentarias Latinoamericanas (PELA). Correo electrónico: ceci_rodriguez@usal.es Orcid: https://orcid.org/00000002-8083-8334
} 


\title{
Elections Under Suspicion. Analysis of the General Elections in Honduras 2017
}

\begin{abstract}
This article addresses the last Honduran electoral process, initiated in March of 2017 with the Primary Elections and concluded on November 26 of that same year with the questioned General Elections that gave as winner to Juan Orlando Hernández, candidate for the official National Party of Honduras (PNH), after prevailing in the polls by a narrow margin of votes that put in prohibition to the Supreme Electoral Court for the suspicion of electoral fraud. To this end, the study describes the main characteristics of the Honduran party system as well as the political, social and economic context prior to the elections, it discusses the electoral processes that took place in 2017; and, finally, it analyzes the results and the consequences of these processes for the party system. As conclusion, we found that the coup d'état of 2009, the electoral results of 2013 and 2017, and the performance of the Government in the socioeconomic field have provoked the citizen discontent, distrust in the traditional political families and the renovation of the Honduran political class.
\end{abstract}

\section{Keywords}

Electoral System; Elections; Political Change; Political Parties; Honduras. 


\section{Introducción}

El 26 de noviembre de 2017 Honduras realizó las décimas elecciones generales desde el retorno a la democracia en 1982 para elegir por un periodo de cuatro años (2018-2022), mediante el voto directo, a las autoridades del país: presidente y tres designados presidenciales, 128 diputados al Congreso Nacional y sus respectivos suplentes, y a los representantes de las 298 corporaciones municipales, e indirectamente a 20 diputados del Parlamento Centroamericano.

Los resultados dieron como ganador a Juan Orlando Hernández, candidato por el oficialista Partido Nacional de Honduras (PNH), tras imponerse en las urnas por un estrecho margen de votos, en unas elecciones muy cuestionadas antes, durante y después de la jornada electoral. El proceso electoral estuvo marcado por numerosas irregularidades y no dejó ajena a la comunidad internacional que, a través de los informes emitidos por los distintos observadores (MOE-UE, 2017; OEA, 2017), coincidieron en señalar las irregularidades de este, provocando la respuesta del Tribunal Supremo Electoral (TSE, 2017, diciembre 22) y la indignación ciudadana por los hechos ocurridos.

\section{Principales rasgos del sistema de partidos hondureño}

Honduras es de los pocos países de la región latinoamericana que durante décadas contó con un sistema bipartidista. Tanto el Partido Liberal de Honduras (PLH), fundado en 1890, como el Partido Nacional de Honduras (PNH), fundado en 1902, ${ }^{1}$ han mantenido siempre una posición central en el sistema político, mostrando con ello una gran capacidad de adaptación a las circunstancias y a las transformaciones de este (Otero, 2014, p. 81).

A lo largo de los años, la mayoría del electorado optó entre azules y rojos con mínima volatilidad —nacionales y liberales respectivamente-, la afiliación partidista se convirtió en un elemento de la identidad de las familias y constituía más un rasgo colectivo que individual (Romero, 2014, p. 14). Así se consolidó un bipartidismo con profundas raíces en el ámbito nacional y caracterizado por presentar una escasa polarización ideológica y estar escorado a la derecha del espectro político, tal como puede observarse

\footnotetext{
${ }^{1}$ El Partido Nacional de Honduras (PNH) nació como producto de una escisión del Partido Liberal de Honduras (PLH). Ambas organizaciones políticas tienen su origen vinculado a los intereses de las compañías bananeras estadounidenses Unit Fruit Company y Cuyamel Fruit.
} 
en la gráfica 1. Esta exigua diferenciación ideológica ha hecho posible que los partidos se hayan nutrido de una gran diversidad de sectores sociales, sin descuidar su maquinaria clientelar.

Gráfica 1. Ubicación ideológica de los partidos tradicionales (1994-2014).²

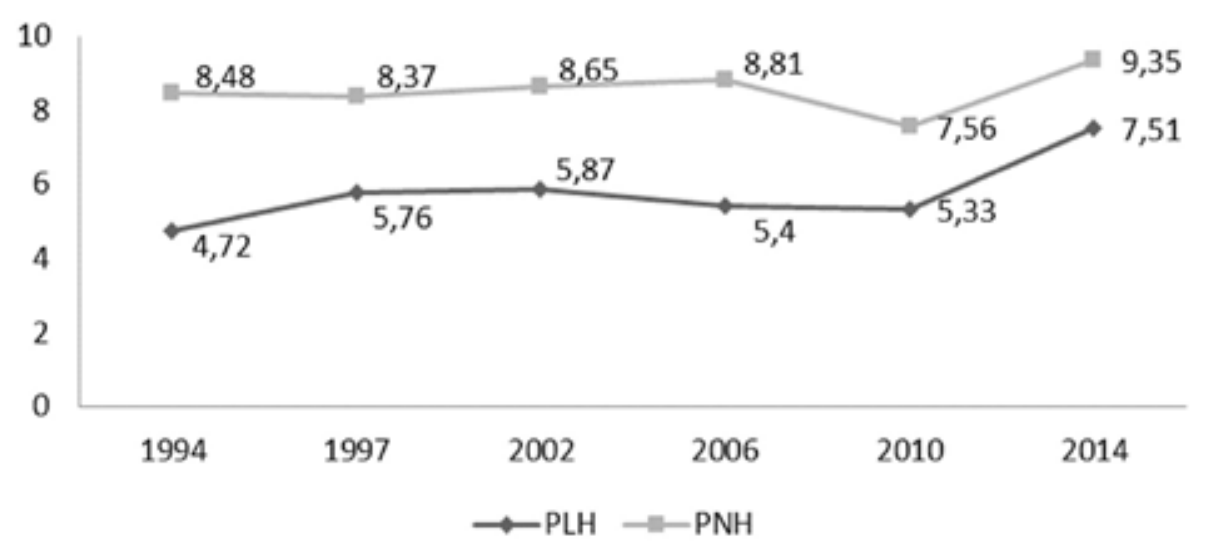

Fuente: elaboración propia a partir de Élites (s. f.).

Hasta 2009 el sistema de partidos hondureño contaba con cinco partidos políticos. A los tradicionales PLH y PNH se sumó el Partido Innovación y Unidad Social Demócrata (PINU-SD), ${ }^{3}$ el cual obtuvo en 1980, por primera vez, tres bancas de las 71 para conformar la Asamblea Constituyente; en las elecciones de 1981 se incorporó el Partido Demócrata Cristiano de Honduras (PDCH); ${ }^{4}$ finalmente, en 1997 lo hizo el Partido Unificación Democrática $(\mathrm{PUD})^{5}$ (Rodríguez, 2018, p. 260). Sin embargo, la contienda electoral en las

\footnotetext{
${ }^{2}$ La pregunta formulada es: «Cuando se habla de política se utilizan normalmente las expresiones izquierda y derecha. En una escala donde el 1 es la izquierda y el 10 la derecha, ¿en qué casilla colocaría Ud. a los siguientes partidos?». No se pregunta por el partido al que pertenece el entrevistado. ${ }^{3}$ Fundado en 1970 a raíz del Comité Cívico por la Defensa Nacional tras la guerra con El Salvador (1969). Se inscribió legalmente en el entonces llamado Consejo Nacional de Elecciones en 1978.

${ }^{4}$ Partido con origen en el Movimiento Demócrata Cristiano de Honduras, constituido como partido político a finales de la década de 1970, aunque solo pudo inscribirse legalmente en 1980, en pleno proceso de transición política.

${ }^{5}$ Tras los Acuerdos de Paz de Esquipulas, Unificación Democrática (UD) aglutinó diferentes grupos de la izquierda hondureña que permanecían en la ilegalidad o que habían escapado del país debido a la persecución política. Fue reconocido legalmente en 1993, e inscrito en el Tribunal Nacional de Elecciones en 1994.
} 
elecciones presidenciales siempre giró en torno a los dos partidos tradicionales, los cuales concentraban un mayor porcentaje de votos.

Las condiciones excepcionales generadas por la crisis tuvieron un impacto directo en el mapa partidista hondureño, dando lugar a la formación de cuatro fuerzas políticas. Dos de ellas procedentes del Frente Nacional de Resistencia Popular (FNRP) ${ }^{6}$ y situadas a la izquierda del espectro ideológico: por un lado, el Partido Libertad y Refundación (Libre), que ha sido refugio de muchos liberales que abandonaron el partido. La segunda es el Frente Amplio Político Electoral en Resistencia (Faper), liderada por el activista de los derechos humanos Andrés Pavón.

La reacción crítica al bipartidismo tradicional también se manifestó por la creación de dos fuerzas conservadoras: por un lado, la Alianza Patriótica Hondureña, con una visible presencia de exmilitares, encabezado por el exgeneral Romeo Vásquez, uno de los actores de la crisis de 2009 en calidad de comandante de las Fuerzas Armadas; y por otro, el Partido Anticorrupción (PAC) (Otero, 2013; Rodríguez, 2015), ${ }^{7}$ liderado por el popular comentarista deportivo Salvador Nasralla.

De este modo y por primera vez en décadas, aumentó el número de partidos en Honduras con la inscripción en 2012 de cuatro nuevos partidos. Estos fueron, de algún modo, la traducción política de los intereses en conflicto tras el golpe de Estado y la diversidad de posturas derivadas de ese suceso.

Las huellas de esta crisis quedaron en evidencia con los resultados de las elecciones de 2013. En estos comicios, el PNH ganó la presidencia, logrando por primera vez dos mandatos consecutivos, pero los buenos resultados obtenidos por ambas fuerzas políticas - Libre y PAC — , unidos a la debilidad manifiesta del PLH, confirmaron la transformación del sistema de partidos hondureño.

\footnotetext{
${ }^{6}$ Congregó, desde las primeras horas del golpe, diversos movimientos sociales, así como sectores críticos e indiferentes con la gestión de los partidos tradicionales, entre estos se encontraban: miembros del Bloque Popular, asociaciones obreras y campesinas, miembros de la UD, disidentes de PINU, y una gran masa de liberales pro-Zelaya. Este movimiento, con origen en la capital, fue extendiéndose al resto del país, construyendo la identidad del cambio político que simbolizaba la convocatoria de una Asamblea Nacional Constituyente (Cálix, 2010).

${ }^{7}$ Surgió como una fuerza conservadora, identificado por los legisladores de otros partidos del periodo actual (2014-2018) en la escala ideológica del 1 al 10, con un 5,7.
} 


\section{Contexto previo a las elecciones}

Sin duda, el hecho político de mayor relevancia que marcó el año electoral fue el fallo de la Sala Constitucional de la Corte Suprema de Justicia a favor de los recursos que habían interpuesto el expresidente Rafael Callejas y diputados del PNH y del PUD. Estos pedían derogar el artículo 239 que preveía la prohibición de la reelección presidencial, así como el 42.5 que establece la pérdida de ciudadanía por promover o incitar la reelección presidencial.

De esta manera, a inicios de 2016 la Corte Suprema, integrada por una mayoría de miembros próximos al oficialismo, ${ }^{8}$ declaró inaplicables los artículos de la Constitución que prohibían la reelección presidencial y posibilitó que, por vez primera, desde la promulgación de la Constitución de 1982, un presidente en ejercicio, aspirara a su reelección. ${ }^{9}$ Indudablemente, la posibilidad de una reelección presidencial, que ya desencadenó el golpe de Estado de 2009, sobrevoló un proceso electoral polarizado.

En el ámbito social, uno de los principales problemas que afecta a la sociedad hondureña es la persistencia de los elevados niveles de violencia y

[208] criminalidad. En la gráfica 2 se observa cómo Honduras vivió una escalada de criminalidad sin precedentes desde 2004, cuya tasa de homicidios pasó de 30,7 casos por cada cien mil habitantes a 86,5 en 2011, momento más álgido de la violencia en el país, que lo colocó entre los países más violentos del mundo. La tasa de homicidios en 2017 fue de 43,6 víctimas por cada cien mil habitantes; la mayoría en los municipios de Tegucigalpa y San Pedro Sula, los dos mayores centros urbanos del país. Pese a la reducción de 15,5 puntos de la tasa de homicidios con respecto a $2016(59,1)$, Honduras continúa siendo uno de los países más violentos de la región, ubicándose en el cuarto lugar detrás de Venezuela (89), El Salvador $(60)$ y Jamaica $(55,7)$, presentando, además, niveles más altos que su vecina Guatemala $(26,1)$ (Insightcrime, 2018, enero 19).

\footnotetext{
${ }^{8}$ Ocho de los magistrados que integran la Corte Suprema son allegados al PNH y siete al PLH.

${ }^{9}$ Los antecedentes de continuismo presidencial se remontan a Tiburcio Carías, quien fue reelecto ininterrumpidamente desde 1933 hasta 1949. Ningún mandatario hondureño buscó la reelección desde el regreso de la democracia, salvo la frustrada reforma constitucional de Manuel Zelaya en 2009, que provocó el Golpe de Estado, o la estrategia, igualmente frustrada, de Roberto Suazo Córdova en 1985 de continuar en el cargo.
} 
Gráfica 2. Muertes por homicidios.

Comparativo 2004-2017 (tasas x 100.000 hab.).

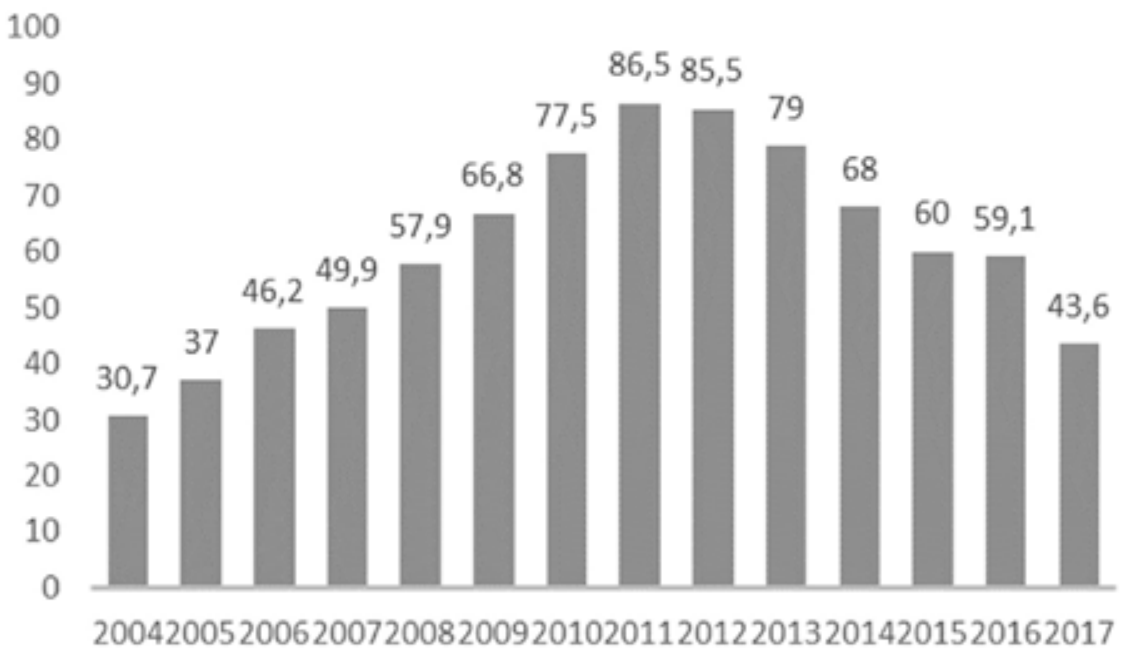

Fuente: elaboración propia a partir de ludpas (s. f.).

Los elevados niveles de violencia en el país han motivado un endurecimiento de las políticas de seguridad en las últimas administraciones del partido nacional. A pesar de la alta tasa de criminalidad, la política de seguridad y la lucha contra la delincuencia es probablemente el elemento más destacable de la gestión de Hernández (2014-2018) (Otero y Rodríguez, 2016). Las políticas de «mano dura», centradas en el control de la seguridad por parte de los militares, comenzaron en la gestión nacionalista de Porfirio Lobo (2010-2014) ${ }^{10}$ y se acentuaron más aún durante la gestión de Hernández, con la creación de la Tropa de Inteligencia y Grupos de Respuesta Especial de Seguridad (Tigres). ${ }^{11}$

Si bien la disminución de la tasa de violencia puede analizarse como un éxito de la gestión de Hernández, no puede decirse lo mismo en el ámbito económico. Tal como puede observarse en la gráfica 3, la tasa de desempleo ha ido en constante aumento desde 2009, momento en que se desencadena la crisis política que dio lugar al golpe de Estado. En 2012, durante el gobierno

\footnotetext{
${ }^{10}$ Durante este periodo el Congreso aprobó numerosas medidas en este sentido, entre ellas: la Tasa de Seguridad, la extradición a Estados Unidos de los narcotraficantes, un decreto para depurar la Policía Nacional, la creación de la Dirección de Investigación y Evaluación de la Carrera Policial (DIECP), la conformación de la Comisión de Reforma de la Seguridad Pública (CRSP) y, por último, la Policía Militar del Orden Público (PMOP) (Rodríguez, 2014).

${ }^{11}$ Unidad de élite subordinada a la Secretaría de Defensa y adscrita a la Policía Nacional Preventiva, cuya labor principal es la lucha contra el crimen organizado.
} 
de Lobo $(\mathrm{PNH})$ se registró una leve disminución, aunque el aumento ha sido constante y notorio durante la gestión de Hernández.

Gráfica 3. Evolución de la tasa de desempleo, 2005-2016.

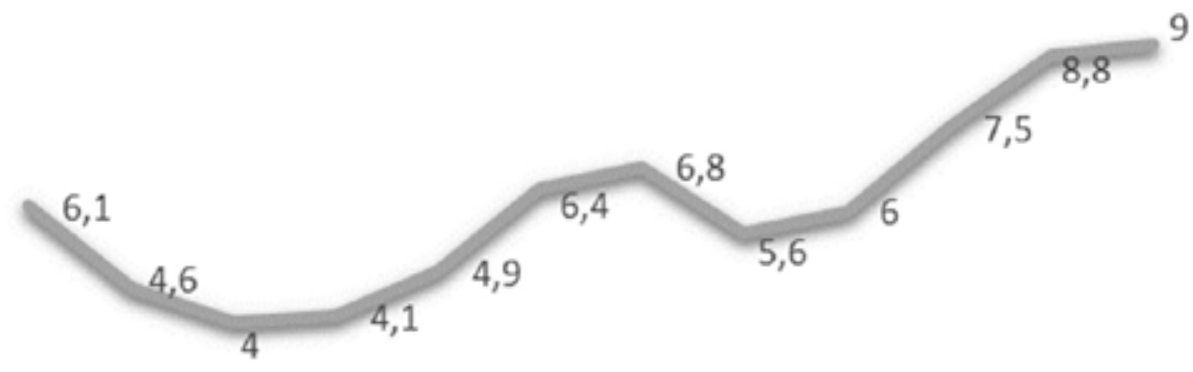

\section{6}

Fuente: elaboración propia a partir de Cepal (s. f.).

[210] Según el Instituto Nacional de Estadísticas (INE, 2016), de una población de aproximadamente 8680049 personas, 65,7\% —5 699879 personas- se encontraban en condiciones de pobreza, de los cuales $42,5 \%$ -3 686641 personas - estaban en condiciones de pobreza extrema. Del total de asalariados, $71,6 \%$ — 940 777_ recibían por debajo de un salario mínimo, y de los ocupados 55,7\% estaba en la categoría de subempleo. Para 2017 estos indicadores empeoraron. Las personas en condición de pobreza aumentaron a 68,8\% -6 079082 personas-, de los cuales $44,2 \%-3902$ 122 personas - estaban en condición de pobreza extrema. Aunado a ello, el subempleo es de $56 \%$ y $75,4 \%$ de los asalariados - 1328697 - recibe menos de un salario mínimo.

Estos datos reflejan la delicada situación económica que atraviesa el país. Asimismo, la desigualdad de ingreso en Honduras sigue siendo una de las más altas de la región, con un coeficiente GINI de 53,7 (2013), y donde el 20\% peor remunerado representa solo el 3,1\% del ingreso nacional (2013), unas cifras que no parecen mejorar con la aplicación de los numerosos programas sociales impulsados desde el Gobierno (Banco Mundial, s. f.). ${ }^{12}$

${ }_{12}$ Tales como el Bono Diez Mil - antes Vida mejor-, la Bolsa Solidaria, los Techos Dignos (Viviendas), el Bono Educativo (becas) o el Bono de la Tercera Edad. 


\section{Elecciones primarias. El pulso de los actores políticos}

El 12 de marzo $2017^{13}$ Honduras realizó un nuevo proceso de elecciones primarias para nombrar candidatos de partidos a cargos de elección en los ámbitos presidencial y designados, parlamentario nacional y centroamericano, autoridades de gobiernos locales, y la composición de las directivas internas de los partidos políticos. ${ }^{14}$ Este proceso electoral es de vital importancia porque las elecciones presidenciales de noviembre se deciden en primera vuelta, por simple mayoría, convirtiendo a las primarias en un pulso de carácter político en el que los partidos miden sus fuerzas de cara a las elecciones generales.

Estas elecciones contaron con la participación de diecisiete movimientos internos pertenecientes a tres partidos políticos (PLH, PNH y LIBRE). Los dos partidos tradicionales (PLH y $\mathrm{PNH}$ ) eligieron sus candidatos presidenciales una vez más, a través de elecciones primarias, como vienen haciendo desde 1992 en el Partido Liberal y desde 1997 en el Partido Nacional. En el caso de Libre, es la segunda vez consecutiva que participa en este proceso. El resto de los partidos no realizó primarias al no contar con movimientos internos reconocidos. En estas elecciones, el movimiento que gana la candidatura presidencial tiende a acaparar los espacios de dirección y la estructura del partido, pero necesita del apoyo de todos los sectores, con el objetivo de ganar en los comicios generales. Así, la diferencia entre las facciones reside en cuánto poder han acumulado en los procesos internos y cuánto pueden negociar (Taylor-Robinson, 2009; Otero, 2013; Rodríguez, 2011).

Es pertinente destacar que la selección de candidatos a diputados y alcaldes se realiza desde 2005. Previo a esa fecha, los precandidatos presidenciales proponían planillas para el Congresoylaselecciones municipales, pero las papeletas se fusionaban y los resultados eran considerados solamente consultivos (Taylor-Robinson, 2009).

\footnotetext{
${ }^{13}$ Las elecciones primarias e internas se realizan el segundo domingo de marzo, cada cuatro años, ocho meses antes de las elecciones generales, según lo establece la reforma al artículo 113 de la Ley Electoral de Honduras de 2014.

${ }^{14}$ La Ley Especial Relativa a las Elecciones Internas Directas y Generales de Autoridades Supremas y Municipales (Decreto 89-85) estableció para el proceso electoral de 1985 la obligación de realizar elecciones primarias y generales simultáneas en los partidos políticos que tuvieran movimientos internos reconocidos.
} 
Los partidos son distintos con respecto a su nivel de faccionalización (véase tabla 1), siendo el PLH el que más facciones internas ha presentado históricamente, aunque estas no se caracterizan por presentar diferencias de carácter ideológico, sino que están estrechamente relacionadas con la existencia de liderazgos al interior del partido y a los lazos que estos tengan con algunos sectores de la sociedad (Rodríguez, 2015). En esta oportunidad, cinco movimientos liberales participaron de la contienda, resultando vencedor el «Movimiento por Honduras, por Nosotros», con Luis Zelaya como candidato.

Tabla 1. Resultados elecciones primarias 2017.

\begin{tabular}{|c|c|}
\hline & Voto obtenido \% \\
\hline \multicolumn{2}{|c|}{ Partido Liberal de Honduras (PLH) } \\
\hline Carlos Orbin Montoya (Alianza Popular Progresista) & 2,54 \\
\hline Educado Martell (Nueva Actitud) & 3,47 \\
\hline Luis Zelaya (Por Honduras Por Nosotros) & 56,88 \\
\hline Enrique Ortez Sequeira (Movimiento Unamonos) & 4,14 \\
\hline Gabriela Núñez (Nuevo Liberalismo) & 32,97 \\
\hline \multicolumn{2}{|c|}{$\begin{array}{ll}\text { Partido Nacional de Honduras (PNH) }\end{array}$} \\
\hline Roberto Ramón Castillo (Monarca) & 7,44 \\
\hline Juan Orlando Hernández (Alianza PN Unidos y Juntos) & 92,56 \\
\hline \multicolumn{2}{|c|}{$\begin{array}{ll}\text { Partido Libertad y Refundación (Libre) } \\
\end{array}$} \\
\hline Rasel Tomé (Movimiento Renovación Partido Libre) & 3,40 \\
\hline Nelson Ávila (Movimiento 5 De Julio) & 2,71 \\
\hline $\begin{array}{l}\text { Xiomara Castro (Alianza Presidencial Movimiento } \\
\text { M28. POR. FRP. PLI. AVA. SOM. FE) }\end{array}$ & 93,89 \\
\hline
\end{tabular}

Fuente: elaboración propia a partir de TSE (2017).

Por el PNH se presentaron tres movimientos internos, aunque dos de ellos (Juntos por Más Cambios y Unidos por la Nueva Honduras) impulsaron la candidatura del actual presidente Hernández. Por último, Libre contó con la participación de nueve movimientos internos, aunque el proceso electoral se dirimió entre tres de ellos, resultando vencedora - por un amplio margenla coalición formada por los movimientos que apoyaron la candidatura de Xiomara Castro, esposa del expresidente Manuel Zelaya.

Los resultados arrojados definieron varios de los presidenciables y mostraron el camino a seguir. En primer lugar, pusieron de manifiesto al amplio apoyo electoral hacia la candidatura de Hernández, quien se proclamó ganador por el $\mathrm{PNH}$; asimismo, se definió la candidatura de Luis 
Zelaya por el PLH; y, en tercer lugar, dejó constancia de la necesidad de aunar fuerzas por parte de los partidos de oposición para tener opciones reales de ganar la contienda electoral en noviembre. Ante esta situación, Libre, que había optado por la candidatura de Xiomara Castro, decidió unirse a Salvador Nasralla —expresidente del Partido Anticorrupción-y al PINUSD, conformando la alianza Oposición Contra la Dictadura en mayo de 2017, resultando Nasralla candidato oficial a la Presidencia de la República, por dicha coalición.

\section{La campaña electoral: ejes temáticos y financiación}

En ausencia de debates entre los nueve candidatos presidenciales y escasos actos masivos, la campaña se caracterizó, sobre todo, por su baja intensidad, prevaleciendo actividades proselitistas puerta a puerta, caravanas motorizadas y pequeños mítines políticos (MOE-UE, 2017, p. 11). Solo los principales candidatos presidenciales celebraron concentraciones multitudinarias en las cabeceras departamentales del país, sobre todo durante las dos últimas semanas de la campaña (La Prensa, 2017, noviembre 19a; Agencia AFP, 2017, noviembre 5).

La campaña fue pobre en términos ideológicos y programáticos, y se desarrolló en un clima de polarización y conflicto constante entre el partido oficialista y los representantes de la Alianza Contra la Dictadura. Así, el debate se dio entre dos opciones opuestas: los defensores de la continuidad del presidente y los detractores de la prolongación de su mandato. El PNH, como defensor de la continuidad de su candidato, diseñó una campaña muy centralizada en la que reivindicó la gestión de su candidato a la Presidencia y promovió activamente el voto por todos los candidatos a diputados del partido — voto en línea-, en detrimento de las tradicionales campañas legislativas hondureñas en las que candidatos de un mismo partido compiten entre ellos por el voto dentro del sistema de listas abiertas (Mejía, 2017, julio 28). Esta estrategia estaba orientada a obtener el mayor número de escaños en el Poder Legislativo. Por su parte, el bloque opositor centró su campaña en constantes acusaciones hacia la candidatura del bloque oficialista. En particular, denunció la existencia de nexos de miembros del PNH con grupos ilícitos, entre ellos al hermano del presidente y actual candidato por el PNH (Bonilla, 2017, marzo 29).

No obstante, tres cuestiones han sido objeto de discusión y han ocupado los titulares durante el periodo preelectoral, tanto en gráficas, medios de 
comunicación y redes sociales: la primera tiene que ver con las reiteradas denuncias por parte de la oposición y de la ciudadanía hacia la candidatura del actual presidente, posibilitada por la reelección. La segunda, en el que todos los candidatos electorales han hecho hincapié, es la elevada tasa de violencia que aqueja al país. La tercera fue la necesidad de generar empleo. ${ }^{15}$

Sin duda, durante la campaña el partido oficialista ha contado con una desigualdad de recursos respecto a los demás partidos, derivados de su estatus de gobierno, entre ellos, los que se encuentran asociados con el clientelismo o patronazgo, obtenidos de la distribución de bienes o beneficios en el marco de los programas sociales del Estado. Asimismo, la desigualdad de recursos económicos entre los contendientes en favor del Partido Nacional y de su candidato fue evidente en el acceso a los medios de comunicación. En este sentido, la cobertura brindada por los medios de comunicación a los distintos candidatos se explica, en primer lugar, por la desigual distribución de recursos obtenida por el financiamiento público, en función de los últimos resultados electorales conseguidos por los partidos. ${ }^{16} \mathrm{Y}$ en segundo lugar, el mecanismo de canje de deuda fiscal por propaganda le ha otorgado al presidente un amplio margen de discrecionalidad para acordar condiciones ventajosas a los medios a la hora de liquidar sus deudas con la administración (MOE-UE, [214] 2017, p. 29). ${ }^{17}$

Con el propósito de evitar estas desigualdades económicas en el financiamiento de las campañas mediante aportaciones privadas, el Congreso Nacional aprobó en 2016 la Ley de Financiamiento, Transparencia y Fiscalización a Partidos Políticos y Candidatos (Decreto 137-2016), conocida como Ley de Política Limpia, con la cual fijó un techo a los gastos con el objetivo de enfrentar la corrupción, el financiamiento ilícito de partidos y candidatos, y la penetración del dinero del narcotráfico y del crimen organizado en las campañas electorales.

\footnotetext{
${ }^{15}$ Las páginas oficiales de los partidos políticos no recogen programa político alguno y tampoco ha sido posible obtenerlo por medios electrónicos. Las ideas expuestas han sido elaboradas a partir de actos de campaña de los candidatos que han sido grabados y facilitadas a la autora de este trabajo.

${ }^{16}$ Según la Ley Electoral y de las Organizaciones Políticas (LEOP) (Decreto 44-2004), los partidos políticos financian sus campañas electorales a través de asignaciones públicas y aportaciones privadas. El financiamiento público, se entrega en dos cuotas: la primera, de $60 \%$, quince días después de la convocatoria a elecciones; y la segunda, de $40 \%$, calculada en función de los resultados obtenidos en el primer trimestre del año posterior a las elecciones.

${ }^{17}$ Desde 2013 la legislación permite a los medios de comunicación cancelar sus deudas fiscales pendientes mediante la publicación o la difusión de publicidad institucional, en las condiciones que establezca la Presidencia de la República.
} 
Si bien se tiene conocimiento acerca de la entrada en vigor de esta ley, aún no ha concluido el proceso de revisiones por parte de la Unidad de Política Limpia —organismo responsable de su control y aplicación-, por tanto, no es posible afirmar si se han aplicado sanciones efectivas por su incumplimiento (Proceso Digital, 2018, octubre 29). Su primera aplicación ha coincidido con un descenso muy notable del gasto estimado en la campaña en 2017 respecto a la anterior en 2013.

\section{Elecciones Generales 2017}

\subsection{Jornada electoral del 26 de noviembre}

Desde 1981 los comicios en Honduras tienen lugar cada cuatro años, el último domingo del mes de noviembre para todos los cargos de elección: presidente, diputados y gobiernos locales. La elección del presidente, así como las de los tres designados presidenciales, se realiza por mayoría simple a una sola vuelta en circunscripción única nacional. ${ }^{18}$ Por su parte, los veinte diputados correspondientes a Honduras en el Parlamento Centroamericano se reparten proporcionalmente entre los partidos políticos en función de los resultados obtenidos por sus respectivos candidatos a la Presidencia, aunque la Ley Electoral garantiza un representante a cada partido, independientemente del resultado de su candidato presidencial.

De los nueve candidatos a la Presidencia —ocho hombres y una mujer-, solo tres contaban con probabilidades para ganar la contienda (Rodríguez, 2017, noviembre 23), el primero de ellos era el presidente en ejercicio, Juan Orlando Hernández (PNH); el segundo, Salvador Nasralla, por la Alianza Contra la Dictadura, de reciente creación, integrada por Libre y por el minoritario PINU; y el tercero, Luis Zelaya (PLH). Este último se impuso en las primarias, presentándose como un outsider. El candidato del liberalismo pretendía recuperar la grandeza que tuvo en otros tiempos el partido y superar la fractura que sufrió tras la crisis política de 2009; sin embargo, no contó con el apoyo popular ni con el apoyo de la totalidad del partido.

\footnotetext{
${ }^{18}$ En lo referente a las elecciones presidenciales, en cada cita electoral se ha elegido al presidente y sus tres designados a una vuelta por mayoría simple en una única circunscripción nacional. Sin embargo, a esta regla general hay que señalar dos excepciones: la elección presidencial de 1985, realizada simultáneamente con las primarias del PLH y PNH; y la de 2005, la cual aplicó la reforma constitucional que incluía en la nómina presidencial el candidato a la vicepresidencia y no los designados.
} 
Los otros seis tenían pocas posibilidades de triunfar. Estos eran: el general Romeo Vásquez Velásquez (Partido Alianza Patriótica Hondureña), uno de los actores de la crisis de 2009 en calidad de comandante de las Fuerzas Armadas; Lucas Aguilera (PDC), líder campesino; Marlen Alvarenga (PAC), única mujer candidata a la Presidencia en estos comicios generales; Alfonso Díaz (PUD); Eliseo Vallecillo, quien hace pocos meses decidió, junto al expresidente de la PDC, Augusto Cruz Asencio, formar parte del partido Va Movimiento Solidario (Vamos); e Isaías Fonseca (Faper), el más joven de los candidatos.

\subsection{Declaratoria de resultados}

La declaratoria de los resultados electorales estuvo marcada por varios desaciertos denunciados públicamente y dejó muy cuestionada las labores del TSE. Luego del cierre de las elecciones, el TSE no brindó información oficial sobre las actas computadas, el país entró en incertidumbre ante el silencio del Tribunal. Los resultados preliminares, con 57\% de las actas escrutadas, se anunciaron el 27 de noviembre, con Salvador Nasralla a la cabeza $(45,17 \%)$, con un margen de casi cinco puntos por encima de Hernández (40,21\%) (La Prensa, 2017, noviembre 27).

[216] Después del anuncio de los resultados preliminares, el sistema de publicación de votos en línea del TSE supuestamente colapsó y no se publicaron más resultados durante más de diez horas. Cuando la transmisión de los resultados se reanudó comenzó a mostrar una reducción gradual, pero consistente, de la ventaja del candidato de la oposición sobre el presidente en el poder. El 29 de noviembre, según los datos publicados por el TSE, ambos candidatos tenían 42,17\% de los votos (La Prensa, 2017, noviembre 29).

Este giro fue recibido con incredulidad y las denuncias de fraude electoral ocuparon un lugar central, quebrando los intentos de la Organización de Estados Americanos (OEA) de lograr un acuerdo entre los dos autoproclamados ganadores presidenciales (La Tribuna, 2017, noviembre 29). A partir del 29 de noviembre, los llamamientos de la Alianza para la movilización social llevaron a sectores de la población a las calles, en manifestaciones masivas en todo el país, ocasionado que el 1.. de diciembre, el presidente declarara el Estado de excepción durante diez días y el toque de queda nocturno.

En este contexto, el TSE procedió, en respuesta a requerimientos internacionales y en presencia de observadores nacionales e internacionales, al reconteo de los votos de las cerca de cinco mil mesas electorales, cuyas 
actas no fueron transmitidas electrónicamente durante la noche de las elecciones y que, como se señaló, determinaron que Hernández pasara paulatinamente a encabezar el escrutinio. El recuento no arrojó diferencias significativas respecto a los resultados publicados previamente en la página web del Tribunal.

Los resultados finales se dieron a conocer el 17 de diciembre, con una tasa de participación de 57,52\% — de los 6046873 electores censados-, ligeramente por debajo de la registrada en 2013 (61\%) (TSE, 2017a). Hernández fue reelegido con $42,95 \%$ de los votos, con una ligera ventaja de $1,63 \%$ sobre su principal adversario, Salvador Nasralla. Por su parte, Zelaya obtuvo $14,74 \%$, el resultado más bajo obtenido por un candidato liberal en la historia democrática de Honduras. Ninguno de los cinco candidatos restantes alcanzó el 1\%. El rechazo a la declaratoria de los resultados continuó profundizando la crisis del país (La Prensa, 2017, diciembre 18; El Heraldo, 2017, diciembre 17) (véase tabla 2).

Tabla 2. Resultados de las elecciones generales 2017.

\begin{tabular}{|c|c|c|c|c|c|c|}
\hline \multirow[t]{2}{*}{ Candidato presidencial } & \multicolumn{2}{|c|}{$\begin{array}{c}\text { Elección } \\
\text { presidencial }\end{array}$} & \multicolumn{2}{|c|}{$\begin{array}{l}\text { Elección } \\
\text { legislativa }\end{array}$} & \multirow{2}{*}{$\begin{array}{l}\text { Parlacen } \\
\text { Escaños }\end{array}$} & \multirow{2}{*}{$\begin{array}{c}\begin{array}{c}\text { Elección } \\
\text { municipal }\end{array} \\
\text { Alcaldías }\end{array}$} \\
\hline & Votos & $\%$ & $\%$ & Escaños & & \\
\hline $\begin{array}{l}\text { Juan Orlando Hernández } \\
\text { (PNH) }\end{array}$ & 1410888 & 42,95 & 47,66 & 61 & 7 & 173 \\
\hline \multirow{2}{*}{$\begin{array}{l}\text { Salvador Nasralla (Alianza de } \\
\text { Oposición contra la Dictadura } \\
\text { [Libre-PINU]) }\end{array}$} & \multirow[t]{2}{*}{1360442} & \multirow[t]{2}{*}{41,42} & \multirow[t]{2}{*}{26,57} & Libre 30 & Libre 5 & \multirow[t]{2}{*}{ Libre 31} \\
\hline & & & & PINU 4 & PINU 1 & \\
\hline Luis Zelaya (PLH) & 484187 & 14,74 & 20,31 & 26 & 1 & 89 \\
\hline $\begin{array}{l}\text { Romeo Vásquez Velázquez } \\
\text { (Alianza Patriótica) }\end{array}$ & 6517 & 0,20 & 3,12 & 4 & 1 & 1 \\
\hline Marlene Alvarenga (PAC) & 5983 & 0,18 & 0,78 & 1 & 1 & \\
\hline Lucas Aguilera (PDCH) & 5900 & 0,18 & 0,78 & 1 & 1 & 1 \\
\hline Alfonso Diaz Narváez (PUD) & 4633 & 0,14 & 0,78 & 1 & 1 & \\
\hline $\begin{array}{l}\text { Isaias Fonseca Aguilar (Frente } \\
\text { Amplio) }\end{array}$ & 3151 & 0,10 & & & 1 & \\
\hline $\begin{array}{l}\text { Eliseo Vallecillo Reyes } \\
\text { (Vamos) }\end{array}$ & 3003 & 0,09 & & & 1 & 1 \\
\hline Unidos por Esquias & & & & & & 1 \\
\hline $\begin{array}{l}\text { Salvemos Juntos Nuestro } \\
\text { Municipio }\end{array}$ & & & & & & 1 \\
\hline \multicolumn{7}{|l|}{ Independientes } \\
\hline Votos válidos & 3285250 & 94,45 & & & & \\
\hline Votos en blanco & 58816 & 1,63 & & & & \\
\hline Votos nulos & 134899 & 3,88 & & & & \\
\hline Total & 3476419 & 100 & 100 & 128 & 20 & 298 \\
\hline
\end{tabular}

Fuente: elaboración propia a partir de TSE (2017b). 


\subsubsection{Poder Legislativo}

En estas elecciones se contó con una novedad, ya que se aprobó una modificación sobre la forma de marcar las papeletas que permitió la utilización de la raya continua sobre todos los candidatos de un mismo partido, o voto en plancha, en las elecciones al Congreso Nacional. Esta disposición del TSE, a diferencia de la anterior que establecía la obligatoriedad de votar a través de marcas individualizadas para cada uno de los candidatos, tuvo significativos efectos prácticos en el sistema de listas abiertas hondureño. ${ }^{19}$ La modificación sobre la forma de marcar las papeletas fue apoyada por el PNH. Si bien esta modificación recibió fuertes críticas de la Alianza y otros partidos de oposición, no contradice lo establecido en la Ley Electoral (artículo 124), ya que el uso de este tipo de marca no fue obligatorio, sino una opción facultativa que se le brindó al elector.

Los resultados electorales dejaron como corolario un congreso fragmentado, compuesto por ocho de los diez partidos que participaron en las elecciones. Tan solo Faper y el partido de nueva creación Vamos no lograron obtener representación parlamentaria. El PNH, con 61 escaños, trece más que los que tenía en la legislatura anterior, consiguió reforzar notablemente

[218 ] su bancada y se ubicó a cuatro escaños de la mayoría absoluta. Por su parte, Libre obtuvo treinta legisladores, siete menos que en 2013, y el PLH perdió uno, quedando su bancada con veintiséis diputados. El partido PINU, que se alió con Libre en las presidenciales en torno a la Alianza contra la dictadura de Salvador Nasralla pero compitió en solitario en las legislativas, y la Alianza Patriótica de Honduras consiguieron cuatro escaños cada uno, el mejor resultado jamás cosechado por ambos. Además, los PDC y PUD lograron un escaño cada uno. Por su parte, PAC, ya sin su fundador Salvador Nasralla, se desplomó de los trece escaños obtenidos en 2013 a solo un representante.

La tabla 3 permite observar cómo hasta 1993 la proporción de escaños sumados por los pequeños partidos en el poder legislativo eran muy bajos; mientras que en 1997, con la entrada en competición del PUD lograron, en forma conjunta, 5,5\% de los escaños y fueron consolidando su presencia en

\footnotetext{
${ }^{19}$ La LEOP de 2004 puso en marcha el voto preferencial personalizado, incluyendo la fotografía de los candidatos a diputados, dando la opción al elector de cruzar el voto y establecer el orden de preferencia de los representantes. A partir de este momento, quedaba a criterio de elector marcar el total de candidatos como representantes a elegir en el departamento o hacer menos marcas en la papeleta; es decir, se abrió la lista, se desbloqueó y se permitió el voto múltiple manteniendo el sistema de integración proporcional de las planillas (Salomón, 2004; Paz, 2008).
} 
cada una de las citas electorales. La implementación del voto en papeletas separadas desde $1997^{20}$ permitió el crecimiento en el caudal de sufragios en los partidos pequeños que consolidaron su presencia en la Cámara, aunque esta innovación también trajo consigo un aumento considerable de los votos blancos y nulos (Cálix, 2010). A partir de esa fecha y con la excepción de los comicios de 2009, el partido ganador en la Presidencia no logró una mayoría en escaños, teniéndose que apoyar en alianzas con uno de los partidos pequeños. ${ }^{21}$

Los resultados de estas elecciones dejaron como corolario un legislativo muy fragmentado, al igual que en las pasadas elecciones, demostrando de esta manera que los cambios electorales y partidistas de 2013 no fueron coyunturales, sino que, por el contrario, se consolidaron en 2017.

Tabla 3. Evolución de la composición del Congreso Nacional (1981-2017).

Escaños y porcentaje. ${ }^{22}$

\begin{tabular}{|c|c|c|c|c|c|c|c|c|c|c|}
\hline Partido & 1981 & 1985 & 1989 & 1993 & 1997 & 2001 & 2005 & 2009 & 2013 & 2017 \\
\hline PLH & $\begin{array}{c}\mathbf{4 4} \\
53,7 \%\end{array}$ & $\begin{array}{c}67 \\
50 \%\end{array}$ & $\begin{array}{c}56 \\
43,7 \%\end{array}$ & $\begin{array}{c}71 \\
55,5 \%\end{array}$ & $\begin{array}{c}\mathbf{6 7} \\
52,3 \%\end{array}$ & $\begin{array}{c}\mathbf{5 5} \\
43 \%\end{array}$ & $\begin{array}{c}\mathbf{6 2} \\
48,4 \%\end{array}$ & $\begin{array}{c}45 \\
35,2 \%\end{array}$ & $\begin{array}{c}\mathbf{2 7} \\
21.09 \%\end{array}$ & $\begin{array}{c}\mathbf{2 6} \\
20,31 \%\end{array}$ \\
\hline PNH & $\begin{array}{c}34 \\
41,5 \%\end{array}$ & $\begin{array}{c}63 \\
47 \%\end{array}$ & $\begin{array}{c}71 \\
55,5 \%\end{array}$ & $\begin{array}{c}\mathbf{5 5} \\
43 \%\end{array}$ & $\begin{array}{c}54 \\
42,2 \%\end{array}$ & $\begin{array}{c}\mathbf{6 1} \\
47,7 \%\end{array}$ & $\begin{array}{c}54 \\
42,2 \%\end{array}$ & $\begin{array}{c}71 \\
55,5 \%\end{array}$ & $\begin{array}{c}48 \\
37,5 \%\end{array}$ & $\begin{array}{c}61 \\
47,66 \%\end{array}$ \\
\hline PINU & $\begin{array}{c}3 \\
3,6 \%\end{array}$ & $\begin{array}{c}\mathbf{2} \\
1,5 \%\end{array}$ & & $\begin{array}{c}2 \\
1,5 \%\end{array}$ & $\begin{array}{c}\mathbf{5} \\
3,9 \%\end{array}$ & $\begin{array}{c}4 \\
3,1 \%\end{array}$ & $\begin{array}{c}\mathbf{3} \\
2,3 \%\end{array}$ & $\begin{array}{c}\mathbf{3} \\
2,3 \%\end{array}$ & $\begin{array}{c}1 \\
0,78 \%\end{array}$ & $\underset{3,12}{\mathbf{4}} \%$ \\
\hline PUD & & & & & $\begin{array}{c}\mathbf{1} \\
0,8 \%\end{array}$ & $\begin{array}{c}\mathbf{5} \\
3,9 \%\end{array}$ & $\begin{array}{c}\mathbf{5} \\
3,9 \%\end{array}$ & $\begin{array}{c}4 \\
3,1 \%\end{array}$ & $\begin{array}{c}1 \\
0,78 \%\end{array}$ & $\begin{array}{c}\mathbf{1} \\
0,78 \%\end{array}$ \\
\hline PDC & $\underset{1,2}{\mathbf{1}} \%$ & $\begin{array}{c}\mathbf{2} \\
1,5 \%\end{array}$ & $\begin{array}{c}1 \\
0,8 \%\end{array}$ & & $\begin{array}{c}\mathbf{1} \\
0,8 \%\end{array}$ & $\begin{array}{c}\mathbf{3} \\
2,3 \%\end{array}$ & $\underset{3,1 \%}{4}$ & $\begin{array}{c}\mathbf{5} \\
3,9 \%\end{array}$ & $\begin{array}{c}1 \\
0,78 \%\end{array}$ & $\begin{array}{c}1 \\
0,78 \%\end{array}$ \\
\hline PAC & & & & & & & & & $\begin{array}{c}\mathbf{1 3} \\
10,16 \%\end{array}$ & $\begin{array}{c}\mathbf{1} \\
0,78 \%\end{array}$ \\
\hline Libre & & & & & & & & & $\begin{array}{c}37 \\
28,91 \%\end{array}$ & $\begin{array}{c}30 \\
23,44 \%\end{array}$ \\
\hline $\begin{array}{l}\text { Alianza } \\
\text { Patriótica }\end{array}$ & & & & & & & & & & $\underset{3,12 \%}{4}$ \\
\hline Total & 82 & 134 & 128 & 128 & 128 & 128 & 128 & 128 & 128 & 128 \\
\hline
\end{tabular}

Fuente: elaboración propia a partir de Manuel Alcántara (1999) y TSE (s. f.).

\footnotetext{
${ }^{20}$ Durante el gobierno de Carlos Roberto Reina (1994-1998) se aprobó el voto en papeleta separada. Con esta reforma fue posible que el elector votara por un candidato presidencial y por una planilla de diputados diferente, lo que facilitó el despegue electoral para los pequeños partidos.

${ }^{21}$ Esto sucedió en el gobierno de Ricardo Maduro (2002-2006), con el apoyo del PDCH; en el gobierno de Zelaya (2006-2009), con el apoyo del PUD; y en el primer gobierno de Hernández, con apoyo legislativo cambiante en función de sus necesidades.

${ }^{22}$ Siguiendo la normativa constitucional, las legislaturas se instalan en enero del siguiente año a la realización de elecciones.
} 


\subsubsection{Corporaciones municipales}

Las elecciones municipales pusieron en evidencia la fortaleza de los dos partidos tradicionales y la vigencia de sus redes en el territorio hondureño. El PNH ganó en 173 de los 298 municipios, lo que representa un notable avance respecto a 2013 y le permite acceder a nuevos gobiernos locales en departamentos donde su implantación tradicional era menor, como Cortés, Santa Bárbara, Yoro y El Paraíso. Por su parte, el PLH obtuvo 91 Alcaldías y recuperó ocho municipios en los departamentos de Francisco Morazán, Yoro, Atlántida, Olancho, Santa Bárbara y Valle; es decir, los partidos tradicionales ganaron en $88 \%$ de las corporaciones municipales. Libre, por su parte, mantiene sus 31 alcaldías. El PDCH, la Alianza Patriótica y Vamos se alzaron con una Alcaldía cada uno en Francisco Morazán, Cortés y Copán, respectivamente. Por su parte, solo dos de las 45 listas independientes, Salvemos Nuestro Municipio y Unidos por Esquías en Comayagua, lograron acceder a la Alcaldía.

Sin duda, la continuidad del bipartidismo subnacional está vinculada al carácter rural de la mayoría de los departamentos del país, donde el caciquismo y las estructuras partidarias siguen siendo instituciones clave (Barrachina, [220 ] 2014; Rodríguez, 2015). Así, las raíces históricas del PLH y PNH, junto con la capacidad de movilizar su maquinaria en la búsqueda y movilización del voto local, han sido aspectos que les han permitido mantenerse a ambos partidos como los dueños del poder local.

El éxito de Libre en el ámbito subnacional puede explicarse por la cobertura nacional y social heredera del Frente, así como también por su relación privilegiada con los sindicatos del sector público, campesinos y estudiantes, además del hecho de acoger gran número de simpatizantes de partidos tradicionales, sobre todo liberales.

\subsection{Tensiones poselectorales}

En el contexto de una elección muy ajustada, en la que tanto Nasralla como Hernández se declararon vencedores la noche del 26 de noviembre, la inversión de la tendencia de los resultados a medida que avanzaba el escrutinio y las dudas sobre la integridad del sistema provocadas por la sustitución de uno de los servidores del TSE contribuyeron decisivamente al aumento de la tensión poselectoral. 
La oposición se movilizó para denunciar lo que consideró un fraude electoral a favor del candidato oficialista. Durante algunas de las manifestaciones convocadas en diversos puntos del país se produjeron enfrentamientos entre los manifestantes y las fuerzas del orden, que en ocasiones fueron acusadas de recurrir a un uso excesivo de la fuerza. Los enfrentamientos se saldaron con un elevado número de víctimas mortales (BBC Mundo, 2017, diciembre 18).

El Gobierno decretó el $1 .^{\circ}$ de diciembre un toque de queda que suspendió durante diez días la libertad de movimiento durante la noche y de cuyo cumplimiento quedaron exentos, entre otros, los periodistas acreditados por el TSE — la exención fue posteriormente ampliada al resto- y los observadores electorales.

Entre las numerosas denuncias de fraude y los constantes reclamos por parte de los actores políticos implicados, los observadores internacionales comenzaron a manifestarse. Así, la MOE-UE emitió una declaración en la que afirmaban que se identificaban diversas irregularidades. La OEA (2017) presentó un informe mucho más contundente, en el que afirmaban que proceso electoral estuvo caracterizado por irregularidades y deficiencias, de las que se citaban: intrusiones humanas deliberadas en el sistema informático; eliminación intencional de rastros digitales; imposibilidad de conocer el número de ocasiones en que el sistema fue vulnerado; valijas de votos abiertas o sin actas; improbabilidad estadística extrema respecto a los niveles de participación dentro del mismo departamento; y papeletas de voto en estado de reciente impresión; entre otras. Por ello, la OEA manifestó con rotundidad que las irregularidades, sumadas a la estrecha diferencia de votos entre los dos candidatos más votados, hacían imposible determinar con la necesaria certeza al ganador.

No obstante, David Matamoros, presidente del TSE e integrante del Partido Nacional oficialista, el 17 de diciembre — veintiún días después de las elecciones- declaró ganador a Juan Orlando Hernández. Ante esta situación, la OEA expresó pocas horas después su rechazo a los resultados debido a la flagrante evidencia de irregularidades y pidió repetir elecciones dentro del respeto al Estado de derecho, con las garantías de un TSE con la capacidad técnica y la confianza de la ciudadanía y de los partidos políticos. Así, la victoria de Hernández quedó en entredicho poco después de que oficialmente fuera ratificado como presidente de Honduras. 


\subsection{Participación electoral}

Si bien la jornada electoral se llevó a cabo en un persistente clima de violencia social y política, con manifestaciones de diversa naturaleza, lo que intensificó la sensación de inseguridad en la ciudadanía, 57\% del padrón electoral acudió a las urnas. A pesar de ser uno de los porcentajes más bajos registrados desde la instauración democrática, se encuentra por encima del nivel de participación electoral registrado en los comicios de 2009 (véase gráfica 4).

Gráfica 4. Participación electoral (1981-2017), porcentaje.

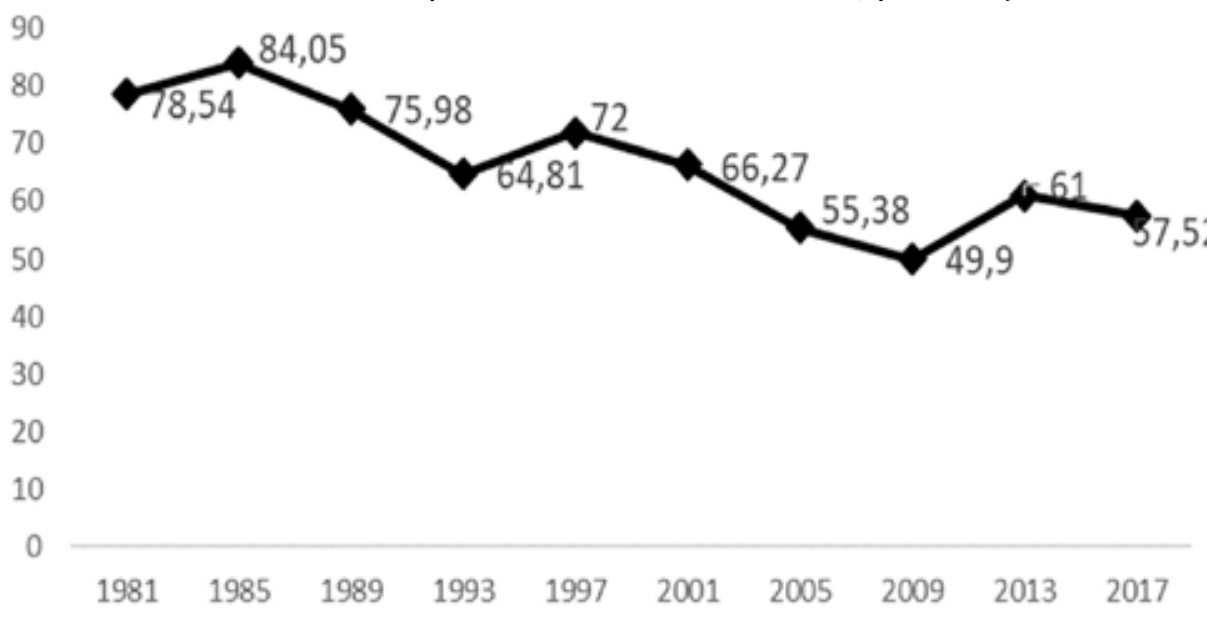

Fuente: elaboración propia a partir de TSE (s. f.).

Es necesario considerar que, en términos porcentuales, la participación electoral podría haber sido mayor si se hubiera saneado el censo electoral, tomando en cuenta que en él están inscritos hondureños fallecidos (Mejía, 2017, septiembre 8). A su vez, muchos hondureños habilitados y deseosos de participar no han podido hacerlo debido a que no poseen su cédula de identificación, necesaria para efectuar el voto (La Prensa, 2017, noviembre 19b) Asimismo, hay que tomar en consideración el número elevado de hondureños que emigraron —la mayoría de ellos hacia Estados Unidos-, los cuales no están en condiciones de ejercer su voto, ${ }^{23}$ aunque un número limitado de ellos se encuentra habilitado para votar.

${ }^{23}$ Ley Especial para el Ejercicio del Sufragio de los Hondureños en el Exterior (Decreto 72-2001), de conformidad al artículo 61 de la LEOP, establece que los ciudadanos residentes en el exterior pueden ejercer el voto para elegir presidente y designados de la República en las elecciones generales en 


\subsection{Presencia de mujeres en el Poder Legislativo}

La LEOP de 2004 incorporó las disposiciones establecidas en la Ley de Igualdad de Oportunidades para la Mujer (Decreto 34-2000). Se determinó el 30\% como el mínimo para la inclusión de mujeres en listas de cargos partidarios y puestos de elección popular, obligando a los partidos a tener una política de igualdad de género e informar sobre su cumplimiento. No obstante, en abril de 2012 se aprobó la reforma a la LEOP para permitir la participación de la mujer en condiciones de igualdad, modificando el artículo 105. Con esta reforma, a partir de las internas y primarias de 2012 las mujeres debían cubrir como mínimo $40 \%$ de las planillas de candidatos para puestos de elección popular, el cual pasaría a 50\% en el proceso electoral de 2017. Además, se determinó la asignación de recursos de 10\% anual por parte del Estado a los partidos políticos para capacitación y promoción política de la mujer. Por otra parte, se delegó en el TSE la reglamentación de este principio de paridad y la implementación de la alternabilidad, también conocido como «trenza» o «cremallera», para alternar en las candidaturas una mujer y un hombre.

Sin embargo, el Reglamento del TSE que detalla las modalidades de aplicación del principio de paridad para los distintos niveles electivos (Acuerdo 3-2016) limita la alternancia efectiva entre hombres y mujeres en las planillas de candidatos a diputados, en abierta oposición al espíritu de Ley Electoral. Así, el Reglamento del TSE establece que la alternancia entre hombre y mujer en las listas al Congreso Nacional es solamente obligatoria a partir de la tercera, cuarta y quinta posición en la planilla, en función de la cantidad de diputados a elegir en cada departamento. ${ }^{24}$

El Reglamento del TSE sí respetó la alternancia en las listas municipales, aunque en la práctica los partidos optaron por hombres como candidatos a Alcaldías en $75,95 \%$ de los casos — primera posición en la planilla

\footnotetext{
Miami, Houston, Los Ángeles, Nueva Orleans, Washington, Nueva York y, desde 2013, Atlanta. En el proceso electoral de 2017 se habilitaron para votar 51000 hondureños, aunque solo votó una cantidad cercana a $5 \%$ (TSE, 2017b).

${ }^{24}$ En el sistema electoral hondureño, la elección de los representantes en el Congreso Nacional es preferencial, pudiéndose elegir de forma directa al candidato de la preferencia del votante, independientemente de su posición en la lista. No obstante, el hecho de situar a las candidatas en posiciones inferiores claramente no favorece la posibilidad de las mujeres de ser electas, como parece deducirse de los resultados de las elecciones de 2017.
} 
municipal—, relegando abrumadoramente a las mujeres a las candidaturas para las Vicealcaldías (75,68\%).

En relación con las candidatas y candidatos electos en el Congreso Nacional para el periodo 2018-2022, solo 27 mujeres (21,09\%) fueron electas, cifra que representa un retroceso respecto a las 33 electas al Congreso Nacional en $2013(25,7 \%) .{ }^{25}$ De las 27 diputadas, trece pertenecen al PNH, ocho a Libre, tres al PLH, dos a la Alianza Patriótica y una al PINU.

Como puede apreciarse en la gráfica 5, el porcentaje de parlamentarias en el Congreso está muy por debajo de la media regional (28,9\%) (ODPI, s. f.) y aún más lejos de la paridad. No obstante, hay una leve mejoría respecto a los primeros procesos electorales, en los que apenas 1,2\% de los escaños durante el periodo 1982-1986 eran ocupados por mujeres.

Gráfica 5. Parlamentarias en el Congreso de Diputados

(1982-2022), en porcentaje.

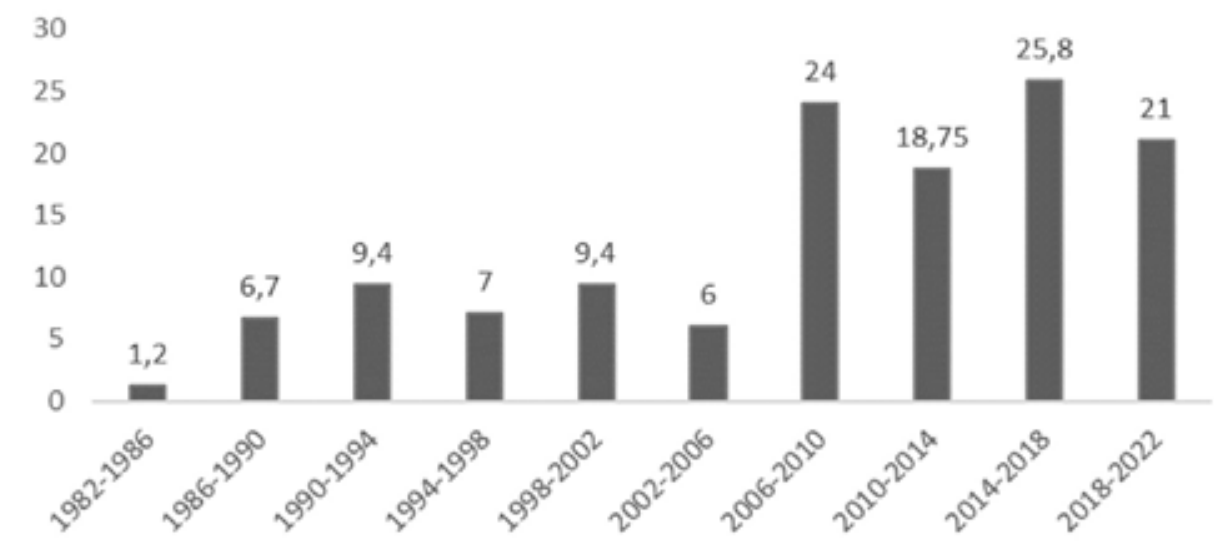

Fuente: elaboración propia a partir de TSE (s. f.).

Si bien las leyes de cuota constituyen una medida de acción afirmativa para incentivar la presencia de más mujeres en los procesos de toma de decisiones, la mera existencia de una normativa legal no asegura la consecución de sus objetivos. Diversos autores han señalado la importancia de ciertos requisitos mínimos que otorguen mayores garantías para su eficacia

${ }^{25}$ También resultaron elegidas 51 mujeres como suplentes. En total, resultaron electas 78 mujeres al Congreso, de los 256 cargos que corresponde entre propietarios y suplentes. 
y que estén enmarcadas en contextos institucionales favorables. Entre estos factores destacan: el carácter mismo de la normativa de cuota, el sistema electoral imperante — proporcional o mayoritario_y el tipo de lista utilizado.

Con respecto a las características propias de la norma, la reglamentación aprobada por el TSE constituye un claro ejemplo del mal diseño, que al no contemplar sanciones efectivas ante el incumplimiento, ni garantizar la alternancia de forma obligatoria en los primeros puestos de las listas electorales, provoca que las mujeres tengan escasas posibilidades reales de acceder al Parlamento.

En relación con el sistema electoral, los métodos de representación proporcional con listas cerradas y distritos grandes son los más favorables para el éxito de las cuotas (Htun y Jones, 2002), ya que permiten la elección de varios candidatos por partido y habilitan el uso de mandatos de posición y de mecanismos de alternancia por sexo. En cambio, las oportunidades de las mujeres disminuyen en los distritos uninominales —donde se elige un único cargo - y pequeños — donde se eligen menos de cinco cargos-, y cuando se utilizan listas abiertas-desbloqueadas y mecanismos de voto preferencial por candidatos.

En el caso hondureño, si bien se cuenta con un sistema electoral con representación proporcional, el tipo de lista es abierta con voto preferencial, siendo este el principal obstáculo para las mujeres. Las listas cerradas o bloqueadas con mandato de ubicación es donde las cuotas tienen un efecto más significativo en la elección de mujeres. Por el contrario, los sistemas que utilizan listas abiertas — como es el caso hondureño— tienen un efecto inverso, aumentando los obstáculos para la elección de mujeres. En estas circunstancias, la competencia intrapartidaria y las limitaciones financieras suelen generar condiciones desfavorables para las candidatas (Marx, Borner y Caminotti, 2007; Franceschet, 2008).

\section{Consecuencias para el sistema de partidos}

\subsection{Número efectivo de partidos parlamentarios}

La reconfiguración del sistema partidario hondureño y su fragmentación quedan de manifiesto en la gráfica 6 . Allí puede apreciarse que el número efectivo de partidos parlamentarios (NEPp) ha registrado un aumento notorio a partir de 2013, pasando de 2,3 en 2009 a 3,58 en 2013; no obstante, se 
observa una leve disminución en las últimas elecciones, producto del bajo desempeño electoral de PAC, que pasó de ocupar trece escaños en el periodo anterior a ocupar uno en este periodo. Este resultado puso en evidencia que la fuerza política de PAC estaba claramente asociada a la figura de su líder, Salvador Nasralla.

Gráfica 6. Número efectivo de partidos parlamentarios, 1981-2017.

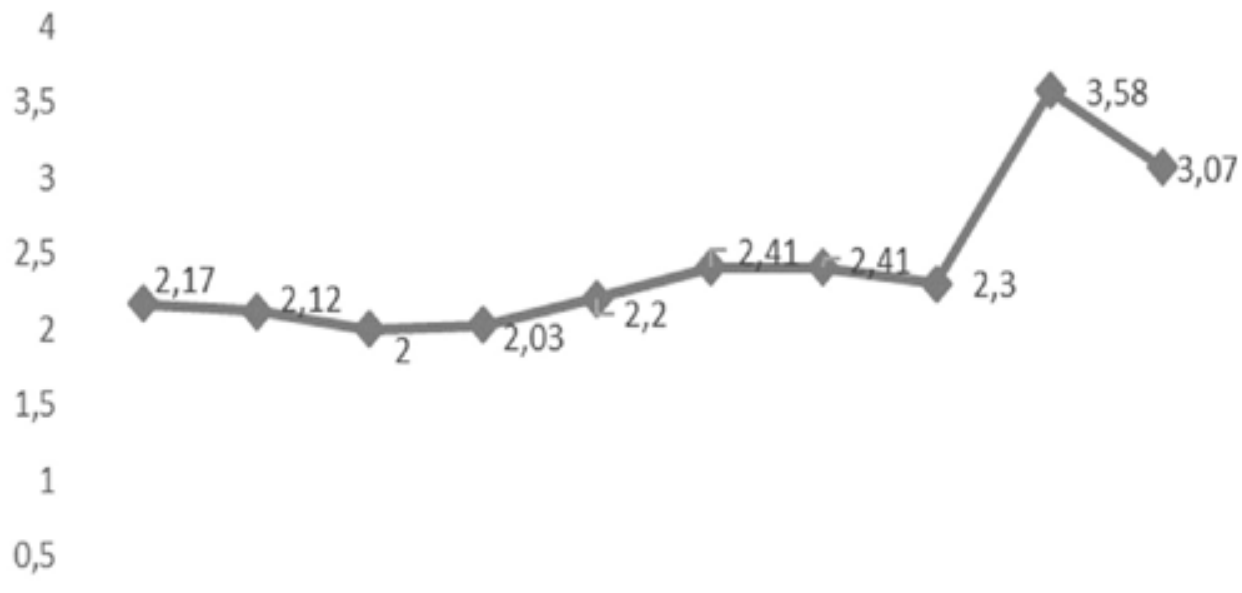

\section{$\begin{array}{llllllllll}1981 & 1985 & 1989 & 1993 & 1997 & 2001 & 2005 & 2009 & 2013 & 2017\end{array}$}

Fuente: elaboración propia a partir de TSE (s. f.) siguiendo la fórmula de Laakso y Taagapera (1979).

\subsection{Concentración electoral}

Los datos contenidos en la gráfica 7 ponen de manifiesto los cambios producidos en el sistema de partidos tras el golpe de Estado. Desde el proceso electoral de 1981 hasta 2009 las dos fuerzas más votadas fueron el PLH y el $\mathrm{PNH}$. Sumaban la mayoría del voto y la alternativa era siempre una de ellas. En 2013, el PNH se impuso con 36,8\%, la cifra más baja desde 1981, y la segunda fuerza más votada no fue un partido histórico, sino el emergente Libre. Ese año saltó por los aires el bipartidismo clásico: Hernández triunfó con un margen electoral de 8,01\% sobre Xiomara Castro — esposa de Manuel Zelaya- de Libre, con 28,9\%; y Mauricio Villeda (PLH) quedó tercero con un escaso $20,28 \%$ de los votos. 
Gráfica 7. Concentración electoral. Porcentaje de apoyo electoral de los dos partidos tradicionales, 1981-2017.

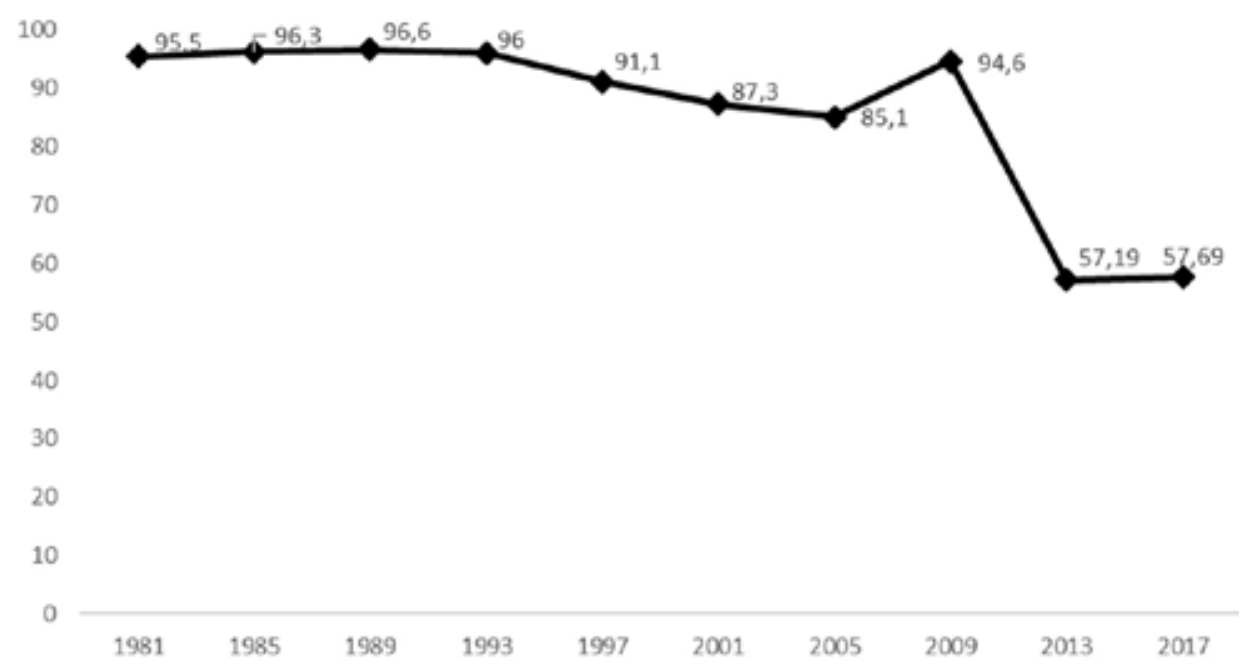

Fuente: elaboración propia a partir de TSE (s. f.)

Sin duda, el clientelismo ha sido el mecanismo que ha permitido fortalecer la concentración electoral durante décadas en ambos partidos tradicionales, reforzando a través de vínculos clientelares y de patronazgo las lealtades partidistas. Así, el intercambio clientelar ha sido el elemento fundamental para la victoria electoral, más que la conexión ideológica o programática con los electores, siendo esta una forma más asequible de satisfacer necesidades inmediatas para la población de escasos recursos, que en Honduras sigue siendo mayoritaria (Otero, 2013, p. 260). El mantenimiento de las redes clientelares ha asegurado el apoyo político durante décadas y ha puesto de manifiesto que las lealtades partidistas dependen del ciclo electoral y de las posibilidades de triunfo de los partidos. A su vez, el arraigo del clientelismo ha impactado también en la implementación de políticas públicas y programas sociales, que muchas veces han acabado beneficiando a los simpatizantes del partido de turno o en el tipo de actividades de los políticos, convertidos en patrones, cuya carrera política depende totalmente del acceso a bienes de diferente tipo (Taylor-Robinson, 2010). Sin embargo, en Honduras los costes del clientelismo han ido aumentando en una sociedad cada vez más numerosa y compleja, cuyas necesidades no han sido satisfechas (Otero, 2013). Estas circunstancias provocaron una notoria disminución 
de la concentración electoral desde las elecciones de 2013, al inclinarse el electorado por nuevas ofertas partidistas.

\section{Consideraciones finales}

Honduras sigue enfrentando un estancamiento en su desarrollo democrático. Los sucesos acaecidos en 2017, derivados de la sentencia de la Sala Constitucional que permitió la reelección presidencial, aunado a las sospechas de fraude que sobrevolaron todo el proceso electoral, acentuaron aún más su crisis democrática. Las instituciones están gravemente afectadas, principalmente el Tribunal Supremo Electoral, cuyos problemas técnicos dejaron en evidencia su capacidad para gestionar un proceso electoral de forma correcta. A esto se suma la permanente situación de violencia que ha generado un mayor protagonismo de las Fuerzas Armadas en la política de seguridad y su participación cada vez mayor en los distintos ámbitos públicos.

Honduras continúa siendo una economía débil. A pesar de que el Gobierno ha tomado algunas medidas necesarias en cuanto al manejo macroeconómico, la tasa de desempleo es cada vez mayor y el escaso trabajo es precario, con los consecuentes problemas de pobreza que eso genera.

[228] Aunque los programas sociales focalizados pueden tener cierto impacto en un sector de la población, no dejan de ser mecanismos muy eficaces de clientelismo político.

En el ámbito político los retos no son menores. Los resultados electorales, tanto de 2013 como de 2017, están dando claras señales del descontento ciudadano que ya no responde a los clásicos mecanismos clientelares que han sostenido la política hondureña. La desaceleración económica y los reclamos de las clases medias han desgastado a los gobiernos y propiciaron nuevas alternativas que se refuerzan gracias a administraciones con sombra de corrupción y sin resultados en áreas centrales como salud, educación, transporte y seguridad ciudadana.

Estas nuevas alternativas políticas que surgieron tras el golpe de Estado de 2009 y que se consolidaron en el último proceso electoral dejan dos aspectos novedosos en la política hondureña: en primer lugar, relegaron al $\mathrm{PLH}$, que tras esta derrota electoral confirma su fractura y debilitamiento; y en segundo lugar, dieron lugar a una renovación de la clase política hondureña, tradicionalmente perteneciente a las mismas familias políticas, al surgir políticos con escasa trayectoria y sin vinculaciones partidistas previas. 


\section{Referencias bibliográficas}

1. Agencia AFP. (2017, noviembre 5). Candidatos presidenciales de Honduras arrecian búsqueda de votos. El Heraldo. Recuperado de https://www.elheraldo.hn/ eleccioneshonduras2017/1123065-508/candidatos-presidenciales-de-hondurasarrecian-b\%C3\%BAsqueda-de-votos

2. Alcántara Sáez, Manuel. (1999). Sistemas políticos de América Latina. Madrid: Tecnos.

3. Banco Mundial. (s. f.). Datos. Recuperado de https://datos.bancomundial.org/

4. Barrachina, Carlos. (2014). Estructuras partidarias y liderazgos en las elecciones hondureñas de 2013. Revista Latinoamericana de Política Comparada, 8, pp. 63-94.

5. BBC Mundo. (2017, diciembre 18). Imágenes de las violentas protestas en Honduras después de que el TSE declarara al presidente Juan Orlando Hernández como ganador de las elecciones. Recuperado de https://www.bbc.com/mundo/ noticias-america-latina-42393078

6. Bonilla, Laura. (2017, marzo 29). El ex capo del narcotráfico que denuncia a la élite de Honduras. El Nuevo Herald. Recuperado de https://www.elnuevoherald.com/ noticias/mundo/america-latina/article141427989.html

7. Cálix, Álvaro. (2010). Honduras: de la crisis política al surgimiento de un nuevo actor social. Nueva Sociedad, 226, pp. 34-51.

8. Comisión Económica para América Latina y el Caribe (Cepal). (s. f.). Bases de datos y publicaciones estadísticas. Recuperado de http://estadisticas.cepal.org/ cepalstat/Portada.html

9. El Heraldo. (2017, diciembre 17). Oposición hondureña desconoce triunfo de $\mathrm{JOH}$ en elecciones presidenciales. Recuperado de https://www.elheraldo. hn/eleccioneshonduras2017/partidoalianza/1135850-508/oposici\%C3\%B3nhondure\%C3\%B1a-desconoce-triunfo-de-joh-en-elecciones-presidenciales

10. Élites. Observatorio de Élites Parlamentarias en América Latina. (s. f.). Recuperado de http://americo.usal.es/oir/Elites/index.htm

11. Franceschet, Susan. (2008). ¿Promueven las cuotas de género los intereses de las mujeres? El impacto de las cuotas en la representación sustantiva de las mujeres. En Marcela Ríos Tobar (ed.). Mujer y política. El impacto de las cuotas de género en América Latina (pp. 61-96). Santiago de Chile: Catalonia.

12. Honduras. Congreso Nacional. Decreto 89-85. (5 de junio de 1985). Ley Especial Relativa a las Elecciones Internas Directas y Generales de Autoridades Supremas y Municipales.

13. Honduras. Congreso Nacional. Decreto 34-2000. (28 de abril de 2000). Ley de Igualdad de Oportunidades para la Mujer. Recuperado de https://www.acnur. org/fileadmin/Documentos/BDL/2016/10637.pdf?file=fileadmin/Documentos/ BDL/2016/10637 
14. Honduras. Congreso Nacional. Decreto 72-2001. (19 de junio de 2001). Ley Especial para el Ejercicio del Sufragio de los hondureños en el Exterior. Recuperado de http://pdba.georgetown.edu/Electoral/Honduras/Leyes/Decreto72-2001.pdf

15. Honduras. Congreso Nacional. Decreto 44-2004. (1. ${ }^{\circ}$ de abril de 2004). Ley Electoral y de Organizaciones Políticas. Recuperado de http://pdba.georgetown.edu/ Parties/Honduras/Leyes/codigoelectoral.pdf

16. Honduras. Congreso Nacional. Decreto 137-2016. (17 de enero de 2017). Ley de Financiamiento, Transparencia y Fiscalización a Partidos Políticos y Candidatos. Recuperado de https://www.tsc.gob.hn/web/leyes/Ley_transparencia_fisc_Partidos_ politicos.pdf

17. Honduras. Tribunal Supremo Electoral. Acuerdo 3-2016. (5 de septiembre de 2016). Reglamento de aplicación del principio de paridad y mecanismo de alternancia en la participación política de mujeres y hombres en los procesos electorales. Recuperado de https://www.tse.hn/web/impp_2016/Documentos/Reglamento_de_ Paridad_y_Alternancia.PDF

18. Htun, Mala y Mark Jones. (2002). Engendering the Right to Participate in Decisionmaking: Electoral Quotas and Women's Leadership in Latin America. In: Craske, Nikki \& Molyneux, Maxine (eds.). Gender and the Politics of Rights and Democracy in Latin America (pp.32-56). London: Palgrave. https://doi. org/10.1057/9781403914118_2

19. Insightcrime. (2018, enero 19). Balance de InSight Crime sobre homicidios

[230] en Latinoamérica en 2017. Recuperado de https://es.insightcrime.org/noticias/analisis/ balance-de-insight-crime-sobre-homicidios-en-latinoamerica-en-2017/

20. Instituto Nacional de Estadísticas (INE). (2016). Encuesta permanente de hogares. Recuperado de http://170.238.108.227/binhnd/RpWebEngine.exe/ Portal?BASE $=\mathrm{EPH} 2016$ \&lang $=\mathrm{ESP}$

21. Instituto Universitario en Democracia, Paz y Seguridad (ludpas). (s. f.). Observatorio de la Violencia. Universidad Nacional Autónoma de Honduras. Recuperado de https://iudpas.unah.edu.hn/observatorio-de-la-violencia/estructura-ymetodologia/

22. La Prensa. (2017, noviembre 19a). Honduras: Candidatos cierran campañas previo a elecciones. Recuperado de https://www.laprensa.hn/inicio/1127404-417/ honduras-candidatos-cierran-campa\%C3\%B1as-previo-a-elecciones

23. La Prensa (2017, noviembre 19b). Hondureños se molestan porque sus cédulas no fueron enviadas. Recuperado de https://www.laprensa.hn/honduras/ elecciones2017/1127284-410/elecciones-honduras-rnp-cedulas-tarjetas-identidad-

24. La Prensa. (2017, noviembre 27). Honduras espera resultados definitivos de elecciones presidenciales. Recuperado de https://www.laprensa.hn/honduras/ elecciones2017/1129944-410/elecciones-honduras-joh-nasralla-candidato_ganadorconteo_votos-actas- 
25. La Prensa. (2017, diciembre 18). Continúan las protestas en Honduras por resultado electoral. Recuperado de https://www.prensa.com/mundo/Continuanprotestas-Honduras-resultado-electoral_0_4920257932.html

26. La Tribuna. (2017, noviembre 29). JOH y Nasralla se comprometen a respetar los resultados ante la OEA. Recuperado de http://www.latribuna.hn/2017/11/29/oeaobtiene-pacto-candidatos-hondurenos-aceptar-resultado-electoral/

27. Laakso, Marku y Taagepera, Rein. (1979). Effective Number of Parties: A Measure with Application to West Europe. Comparative Political Studies, 12 (1), pp. 3-27. https://doi.org/10.1177/001041407901200101

28. Marx, Jutta; Borner, Jutta y Caminotti, Mariana. (2007). Las legisladoras. Cupos de género y política en Argentina y Brasil. Buenos Aires: Siglo xxı.

29. Mejía, Álvaro. (2017, julio 28). Honduras: el voto con raya continua será válido en las elecciones generales. El Heraldo. Recuperado de https://www.elheraldo.hn/ pais/1093833-466/honduras-el-voto-con-raya-continua-ser\%C3\%A1-v\%C3\%A1 lidoen-las-elecciones-generales

30. Mejía, Álvaro. (2017, septiembre 8). Más de 6,1 millones de hondureños podrán votar en elecciones de noviembre. El Heraldo. Recuperado de https://www. elheraldo.hn/eleccioneshonduras2017/1 106504-508/m\%C3\%A1s-de-61-millonesde-hondure\%C3\%B1 os-podr\%C3\%A1n-votar-en-elecciones-de-noviembre

31. Misión de Observación Electoral-Unión Europea (MOE-UE). (2017). Informe Final. Elecciones Generales 2017. Recuperado de https://eeas.europa.eu/electionobservation-missions/eom-honduras-2017/40863/elecciones-generales-en-honduras2017-informe-final-de-la-moe-ue_es

32. Observatorio para la Democracia Paritaria en Iberoamérica (ODPI). (s. f.). Mujeres en Instituciones Políticas. Recuperado de http://odpi.amuger.org/\#Mujeres

33. Organización de Estados Americanos (OEA). (2017). Informe Final. Elecciones Generales 2017. Recuperado de http://scm.oas.org/pdfs/2017/CP38551SMOEH.pdf

34. Otero, Patricia. (2013). El sistema de partidos de Honduras tras la crisis política de 2009. ¿El fin del bipartidismo? Colombia Internacional, 79, pp. 249-287. https:// doi.org/10.7440/colombiaint79.2013.09

35. Otero, Patricia. (2014). Los partidos en Honduras tras el 2009: nuevos actores, nuevos retos. En: De Gori, Esteban (ed.). Honduras 2013: golpe de Estado, elecciones y tensiones del orden político (pp. 80-93). Buenos Aires: Sans Soleil.

36. Otero, Patricia y Rodríguez, Juan Antonio (2016). Honduras: Continuidad en la agenda de gobierno en un nuevo contexto partidista. Revista de Ciencia Política, 36 (1), pp. 195-217. https://doi.org/10.4067/S0718-090X2016000100009

37. Paz, Ernesto. (2008). La reforma política electoral en Honduras. En: Zovatto, Daniel y Orozco Henríquez, Jesús (coord.). Reforma política y electoral en América Latina 1978-2007 (pp. 623-651). México, D. F.: IDEA Internacional.

38. Proceso Digital. (2018, octubre 29). Unidad de Política Limpia presentará segundo informe de auditorías realizada a excandidatos. Recuperado de http:// 
www.proceso.hn/politica-nacional/36-proceso-electoral/unidad-de-politica-limpiapresentara-segundo-informe-de-auditorias-realizada-a-excandidatos.html

39. Rodríguez, Cecilia. (2011). Volver a empezar. Análisis de las elecciones hondureñas tras el golpe de Estado. En: Alcántara, Manuel y Tagina, María Laura (eds.). América Latina: política y elecciones del bicentenario (pp. 213-238). Madrid: Centro de Estudios Constitucionales.

40. Rodríguez, Cecilia. (2014). Panorama político hondureño: crisis de gobernabilidad e inseguridad ciudadana como principales desafíos del nuevo gobierno. Documento de Opinión, 36/2014. Recuperado de http:/www.ieee.es/en/Galerias/ fichero/docs_opinion/2014/DIEEEO36-2014_Honduras_CeciliaGracielaRguez.pdf

41. Rodríguez, Cecilia. (2015). Honduras: hacia una reconfiguración del sistema partidario tras las elecciones generales de 2013. Colombia Internacional, 85, pp. 209226. https://doi.org/10.7440/colombiaint85.2015.07

42. Rodríguez, Cecilia. (2017, noviembre 23). Honduras a la espera de una nueva jornada electoral. Política Exterior. Recuperado de https://www.politicaexterior.com/ latinoamerica-analisis/honduras-a-la-espera-de-una-nueva-jornada-electoral/

43. Rodríguez, Cecilia. (2018). Aires de cambio. Honduras tras las elecciones generales de 2013. En: Alcántara, Manuel; Buquet, Daniel y Tagina, María Laura (eds.): Fin de ciclo: Elecciones recientes y cambio político en América Latina (pp. 257-280). Madrid: Centro de Investigaciones Sociológicas.

44. Romero Ballivián, Salvador (coord.). (2014). Bajo el signo del huracán: [232] elecciones, sistema de partidos, democracia y ciudadanía en Honduras (1948-2013). En: Democracia, elecciones y ciudadanía en Honduras (pp. 9-72). Tegucigalpa: NDI.

45. Salomón, Leticia. (2004). Democracia y partidos políticos en Honduras. Tegucigalpa: CEDOH.

46. Taylor-Robinson, Michelle. (2009). Honduras: una mezcla de cambio y continuidad. Revista de Ciencia Política, 29 (2), pp. 471-489. https://doi.org/10.4067/ S0718-090X2009000200011

47. Taylor-Robinson, Michelle. (2010). Do the Poor Count? Democratic Institutions and Accountability in a Context of Poverty. University Park: Pennsylvania State University.

48. Tribunal Supremo Electoral (TSE). (2017a). Resultados electorales Primarias 2017. Recuperado de http://resultadosprimarias2017.tse.hn/

49. Tribunal Supremo Electoral (TSE). (2017b). Elecciones Generales 2017. Sistema de divulgación. Recuperado de https://resultadosgenerales2017.tse.hn/

50. Tribunal Supremo Electoral (TSE). (2017, diciembre 22). Respuesta del Tribunal Supremo Electoral ante el primer y segundo informe preliminar de la Misión de Observación Electoral de la Organización de Estados Americanos en Honduras. Recuperado de https://elecciones2017honduras.com/wp-content/uploads/2017/12/ Informe-TSE-MOE-OEA-HONDURAS-2017.pdf

51. Tribunal Supremo Electoral (TSE). (s. f.). Estadísticas y procesos electorales. Recuperado de https://www.tse.hn/WEB/estadisticas/procesos_electorales.html 